\title{
Treadmill walking in Parkinson's disease patients: adaptation and generalization effect
}

\author{
Olalla Bello, José Andrés Sánchez, Miguel Fernández-del-Olmo
}

\begin{abstract}
We examined the adaptation and generalization effect of one familiarization treadmill walking session on gait in patients with Parkinson's disease (PD) with different degrees of disease severity. Eight moderate PD patients (Hoehn and Yahr stage 2-2.5), eight advanced PD patients (Hoehn and Yahr 3), and eight matched control subjects participated in this study. Subjects first walked overground on a $10-\mathrm{m}$ walkway at a self-selected speed (pretreadmill). They then performed a 20-min treadmill training session, followed by three trials of overground walking (Post1, Post2, Post3). Cadence, step length, speed, and coefficient of variation of stride time (CV) were recorded. During the treadmill session the advanced PD patients significantly decreased their cadence $(t=3.9, P \leq$ $0.01)$ and increased their step length $(t=4.27, P \leq 0.01)$ compared with pretreadmill walking. After the treadmill, all subjects walked overground significantly faster $(F=16.51 P \leq 0.001)$ and with a larger step length $(F=13.03 P \leq$ $0.01)$ than pretreadmill walking. The present study shows a specific adaptation to walk over the treadmill for the advanced PD patients. Moreover, this confirms the potential therapeutic use of the treadmill for PD gait rehabilitation since a single familiarization session lead to an increase in the step length and thus to the improvement of the main gait impairment in PD.
\end{abstract}

Key words:

Gait; Parkinson's disease; treadmill; physical therapy; rehabilitation

Parkinson's disease (PD) is clinically characterized by symptoms of akinesia, rigidity, and resting tremor related to a dopaminergic deficiency of the nigrostriatal pathway. Disorders of gait are other common symptoms of PD.1 PD gait is characterized by a particular difficulty with the internal regulation of stride length.2, 3 Associated disturbances include a forward-flexed trunk, inadequate flexion at the ankle and knee, insufficient heel strike, reduced arm swing, postural instability, asymmetric stride times for both lower limbs and high stride-to-stride variability.4-9 Although in the first stages of the disease Levodopa therapy is effective in ameliorating these symptoms, with the disease progression the medication treatment loses effectiveness. At this point, the gait performance represents one of the major factors in determining the independence and quality of life of the patients 10 and rehabilitation is highly recommended.11 Thus, one of the main focuses of physical rehabilitation is to improve the gait deficits in PD. In the last decade, a small number of studies have also investigated the use of the treadmill in the rehabilitation of the gait in PD patients, 12-18 Toole and colleagues 15 showed an improvement in the gait and balance in Parkinson's patients that participated in a 6 weeks treadmill walking program. Recently Herman and coworkers18 extended these results showing an enhancement in the gait rhythmicity and several improvements in the motor signs, the later remaining significantly better 4 weeks after the training was stopped. The positive effect of the treadmill in PD seems to be independent of the use of body-weight support.15

Several studies show that one single session with the treadmill can be effective in improving the gait parameters in PD subjects.12, 14 During treadmill walking PD subjects are able to walk with a less variable and more stable gait.17 Pohl and colleagues14 reported an increase in the walking speed, stride length and a decrease in the double stance duration after $30 \mathrm{~min}$ of treadmill training. These immediate effects of treadmill training occurred either when using a progressive speed increase protocol or when walking at the same speed as on overground walking. However, one issue that has not been addressed yet in the literature is whether the adaptation to walk over the treadmill is dependent on the progression of disease. Based on the finding described above, we evaluated the adaptation and generalization effect of one familiarization treadmill session on gait in two groups of PD subjects with different degrees of 
disease severity. We hypothesized that the more advanced PD patients will have a different adaptation to treadmill walking than the moderate PD patients and control subjects.

\section{Patients and methods}

Subjects

Sixteen subjects with PD (9 males and 7 females, mean age $=64 \pm 8.1$ ) and eight age-, sex-, weight-, leg length- and height-matched controls (five males and three females, mean age $=62 \pm 8.3$ ) with no history of neurological disorders were recruited for the study. Eight PD subjects were in the moderate stage (II Hoehn and Yahr stage) and the remaining eight were in the advanced stage group (III Hoehn and Yahr Stage). Seven of the eight advanced patients had freezing phenomena in the OFF state of medication. Both PD and control subjects were recruited from the local community and local Parkinson Association under the supervision of a neurologist and physical therapist. All subjects were naïve to treadmill walking. PD patients were excluded if they had a past history of neurological conditions other than PD or orthopedic, cardiovascular or visual disturbance that affected walking ability. A fundamental requirement for inclusion in the study was the ability to walk for 10 min without stop, walking aids or assistance. For PD subjects, the level of functional disability was also determined by the Unified Parkinson's Disease Rating Scale (UPDRS), the Hoehn and Yahr scale (H\&Y) and the Schwab and England activity of daily living scale (S\&E). No subject showed dementia as assessed by mini-mental state examination (MMSE). All tests were carried out while the patients were ON medication. Details of the subjects are shown in Tables 1 and 2. The Ethics Committee of our Institution approved the experimental protocol and all subjects gave their written informed consent according to the declaration of Helsinki (1964), before entering the study. 
Table 1. Details of Parkinson's disease patient characteristics

\begin{tabular}{|c|c|c|c|c|c|c|c|c|c|c|}
\hline $\begin{array}{l}\text { Patient } \\
\text { number }\end{array}$ & $\begin{array}{l}\text { Age } \\
(\mathrm{yr})\end{array}$ & Sex & $\begin{array}{l}\text { Disease } \\
\text { duration } \\
\quad(\mathrm{yr})\end{array}$ & $\begin{array}{l}\text { Weight } \\
(\mathrm{Kg})\end{array}$ & $\begin{array}{l}\text { Leg } \\
\text { length* } \\
(\mathrm{cm})\end{array}$ & $\begin{array}{l}\text { Height } \\
(\mathrm{cm})\end{array}$ & UPDRS & $\mathrm{H} \& \mathrm{Y}$ & $\mathrm{S} \& \mathrm{E}$ & Medication per day (mg) \\
\hline \multicolumn{11}{|c|}{ Moderate PD patients } \\
\hline 1 & 57 & M & 4 & 96 & 86 & 169 & 32 & 2 & 90 & Levodopa/Carbidopa 300/75, Pramipexole 3.15 \\
\hline 2 & 63 & M & 4 & 71 & 88 & 169 & 35 & 2.5 & 90 & Levodopa/Carbidopa 600/150, Cabergoline 6 \\
\hline 3 & 60 & M & 1 & 66 & 84 & 168 & 28 & 2 & 90 & Levodopa/Carbidopa 600/150, Entacapone 800 \\
\hline 4 & 73 & M & 10 & 79 & 85 & 166 & 48 & 2.5 & 90 & $\begin{array}{l}\text { Levodopa/Carbidopa 875/87.5, Cabergoline } 3 \text {, } \\
\text { Entacapone 400, Pramipexole } 3.15\end{array}$ \\
\hline 5 & 58 & $\mathrm{~F}$ & 12 & 76 & 86 & 164 & 35 & 2.5 & 80 & $\begin{array}{l}\text { Levodopa/Carbidopa 775/137.5, Entacapone 300, } \\
\text { Biperiden 4, Ropinirole } 3\end{array}$ \\
\hline 6 & 59 & $\mathrm{~F}$ & 5 & 73 & 77 & 156 & 38 & 2.5 & 90 & $\begin{array}{l}\text { Levodopa/Carbidopa 300/75, Cabergoline 4, } \\
\text { Entacapone } 600\end{array}$ \\
\hline 7 & 50 & $\mathrm{~F}$ & 6 & 70 & 79 & 156 & 40 & 2 & 90 & $\begin{array}{l}\text { Levodopa/Carbidopa 300/75, Biperiden } 3 \text {, } \\
\text { Entacapone } 600 \text {, Ropinirole } 6\end{array}$ \\
\hline 8 & 66 & $\mathrm{M}$ & 2 & 71 & 80 & 164 & 53 & 2.5 & 80 & Levodopa/Benserazide, 750/187.5, Ropinirole 9 \\
\hline Mean & 61 & & 5 & 75 & 83 & 164 & 39 & 2 & 88 & \\
\hline SD & 6.8 & & 3.8 & 9.4 & 4.0 & 5.5 & 8.3 & 0.3 & 4.6 & \\
\hline \multicolumn{11}{|c|}{ Advanced PD patients } \\
\hline 9 & 61 & $\mathrm{~F}$ & 10 & 74 & 77 & 158 & 86 & 3 & 60 & $\begin{array}{l}\text { Levodopa/Carbidopa 450/112.5, } \\
\text { Levodopa/Benserazide 350/87.5, Cabergoline } 2 \text {, } \\
\text { Entacapone } 1000\end{array}$ \\
\hline 10 & 78 & M & 9 & 79 & 84 & 166 & 53 & 3 & 80 & $\begin{array}{l}\text { Levodopa/Carbidopa 1000/250, Entacapone } 800 \text {, } \\
\text { Cabergoline } 6\end{array}$ \\
\hline 11 & 65 & $\mathrm{~F}$ & 13 & 76 & 82 & 160 & 77 & 3 & 70 & $\begin{array}{l}\text { Levodopa/Carbidopa 1025/275, Entacapone } \\
\text { 1200, Rotigotine } 4\end{array}$ \\
\hline 12 & 73 & M & 14 & 60 & 84 & 162 & 74 & 3 & 80 & $\begin{array}{l}\text { Levodopa/Carbidopa 200/50, } \\
\text { Levodopa/Benserazide 1200/30, Entacapone } \\
\text { 200, Ropinirole } 10\end{array}$ \\
\hline 13 & 74 & M & 7 & 81 & 88 & 167 & 67 & 3 & 70 & Levodopa/Carbidopa 600/75, Ropinirole 18 \\
\hline 14 & 52 & $\mathrm{~F}$ & 8 & 57 & 80 & 159 & 58 & 3 & 70 & $\begin{array}{l}\text { Levodopa/Benserazide 800/200, Pramipexole } \\
3.15\end{array}$ \\
\hline 15 & 63 & $\mathrm{~F}$ & 4 & 79 & 79 & 149 & 45 & 3 & 80 & Levodopa/Carbidopa 450/112.5 \\
\hline 16 & 70 & M & 3 & 84 & 93 & 171 & 51 & 3 & 80 & Levodopa/Carbidopa 300/75, Rotigotina 8 \\
\hline Mean & 67 & & 8 & 74 & 83 & 162 & 64 & 3 & 74 & \\
\hline SD & 8.4 & & 3.9 & 7.2 & 5.0 & 6.7 & 14.4 & 0.0 & 7.4 & \\
\hline
\end{tabular}

*Distance from the great trochanter to the floor. 
Table 2. Details of control subject characteristics

\begin{tabular}{lccccc}
\multicolumn{5}{c}{ Control number Age (yr) Sex Weight (Kg) Leg length (cm) Height $(\mathrm{cm})$} \\
\hline & & & & & \\
1 & 51 & M & 84.5 & 91 & 173 \\
2 & 64 & M & 73.4 & 84 & 170 \\
3 & 61 & F & 63.6 & 82 & 156 \\
4 & 61 & F & 64.9 & 84 & 162 \\
5 & 59 & M & 78.7 & 87 & 170 \\
6 & 74 & F & 76.7 & 82 & 156 \\
7 & 73 & M & 70.6 & 89 & 170 \\
8 & 53 & M & 78.9 & 89 & 175 \\
Mean & 62 & & 74 & 86 & 166 \\
SD & 8.3 & & 9.7 & 3.5 & 7.6 \\
& & & & & \\
\hline
\end{tabular}

\section{Testing Procedure}

The experimental procedure is shown in Figure 1. Prior to testing each subject was given two practice trials of walking overground. The subjects then performed the pretreadmill test (Pre) in which each subject walked up and down the 10-m walkway to complete a total distance of $60 \mathrm{~m}$ at a self-selected comfortable speed. The time taken for each subject to complete the middle $5 \mathrm{~m}$ of the walkway of each lap (30 $\mathrm{m}$ in total) was measured using two pairs of photoelectric cells and the speed $(\mathrm{m} / \mathrm{s}$ ) was calculated. The subjects were then given 5 min to rest in a sitting position before starting the familiarization treadmill session.

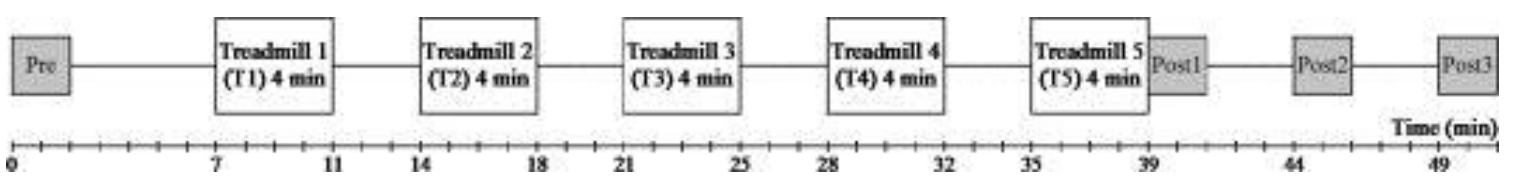

Figure 1. Time line of the experimental procedure.

The familiarization treadmill training session consisted of five 4-min blocks (T1-T5) of treadmill walking with a rest period between blocks of $3 \mathrm{~min}$. All participants walked on the treadmill holding the handrails. The pretreadmill speed was used to set the treadmill speed for each subject. In all blocks, during the first minute, the belt speed was increased to the pretreadmill speed, provided that the subject could walk safely. Measurements on the treadmill were taken in the third minute of each block. Subjects walked on the motorized treadmill under the close supervision of a physical therapist and with a safely harness to prevent falls, which did not support the subject's weight. At the moment that all the participants started to walk over the treadmill the tendency was to increase their cadence and to tilt the body forward. The therapist instructed them to do their steps close to the front of the treadmill and keep erected their body, being careful that all of them received the same amount of feedback. All subjects were asked to hold on to the handrails of the treadmill regardless whether they needed to. Except for the more affected patients, all the subjects were able to walk over the treadmill at their overground comfortable speed from the first block. However, for the advanced PD patients, it was necessary to use a lower speed during T1 and T2 and, in one patient, the T3 blocks since they could not walk safely at the pretreadmill speed. During the T4 and T5 blocks all the advanced PD patients were able to walk at the pretreadmill speed. For these reasons, we choose T5 as the measure that represents best the gait pattern over the treadmill in all the groups.

At the end, three posttreadmill tests were conducted (overground gait): immediately after the treadmill training (Post1), 5 and 10 min after treadmill training (Post2 and Post3, respectively).

The total duration of the experimental session was $1-1.5 \mathrm{hr}$. 


\section{Apparatus}

To measure stride-to-stride time, a force sensitive switch of $2-\mathrm{cm}$ diameter was placed in the subject's shoe corresponding to the position of the heel. The variables measured for each condition of gait included: speed $(\mathrm{m} / \mathrm{s})$; step length $(\mathrm{m})$; cadence $(\mathrm{steps} / \mathrm{min})$ and the coefficient of variation $(\mathrm{CV})$ of recorded intervals between two consecutive steps. Average step length was calculated by dividing the cadence by the gait speed. A treadmill with handrails (SporsArt 6300, Sports Arts Fitness) was used.

\section{Statistical Analysis}

To determine the changes in gait over the treadmill, a repeated-measures analysis of variance (ANOVA) was performed with group (control, PD moderate and PD advanced) and time (pretreadmill, T5) as factors.

A repeated-measures ANOVA was carried out for the following variables: the mean speed, cadence, step length, and coefficient of variation. The independent variables were group (control, PD moderate and PD advanced) and time (pretest and Post1, Post2, Post 3 ), producing a $3 \times 4$ mixed model ANOVA with repeated measures on the latter factor.

Post Hoc $t$ tests were computed using a Bonferroni correction.

All statistical analyses were performed using SPSS (SPSS, Chicago, IL). None of the data violated the normality assumption necessary to conduct parametric statistical tests. A $P$ value $\leq 0.05$ was considered statistically significant.

\section{Results}

Baseline

Baseline characteristics (pretreadmill test) of the subjects in the three groups differed significantly. One way ANOVA showed a main effect for speed $\left(F_{2,21}=22.48, P \leq 0.001\right)$, step length $\left(F_{2,21}=22.43, P\right.$ $\leq 0.001)$ and $\mathrm{CV}\left(F_{2,21}=16.88, P \leq 0.001\right)$ but not for the cadence. Post hoc analysis showed that the three groups were significantly different for speed and step length $(P \leq 0.05)$. CV was significantly different between control and advanced PD patients $(t=4.25, P \leq 0.01)$, and moderate and advanced PD patients $(t=4.98, P \leq 0.01)$ but not between control and moderate PD patients. In line with the literature, the PD patients showed a lower speed and amplitude than control subjects. These differences increased with the severity of the disease.

\section{Overground Gait vs. Treadmill}

The ANOVA showed significant interactions (group*time) for step length $\left(F_{2,21}=13.68, P \leq 0.001\right.$; effect size $(\mathrm{EZ})=0.56$; observed power $(\mathrm{OP})=99 \%)$ and cadence $\left(F_{2,21}=12.56, P \leq 0.001 ; \mathrm{EZ}=0.54\right.$; $\mathrm{OP}=99 \%)$. No interactions between group and time were found for the $\mathrm{CV}$.

During the treadmill session (T5), the advanced PD patients significantly decreased their cadence $(t=$ $3.9, P \leq 0.01)$ and increased their step length $(t=4.27, P \leq 0.01)$ compared with pretreadmill walking. The control subjects and moderate PD patients did not change significantly neither step length nor cadence. Figure 2 demonstrates the adaptation of the subjects in the three groups to the treadmill. 

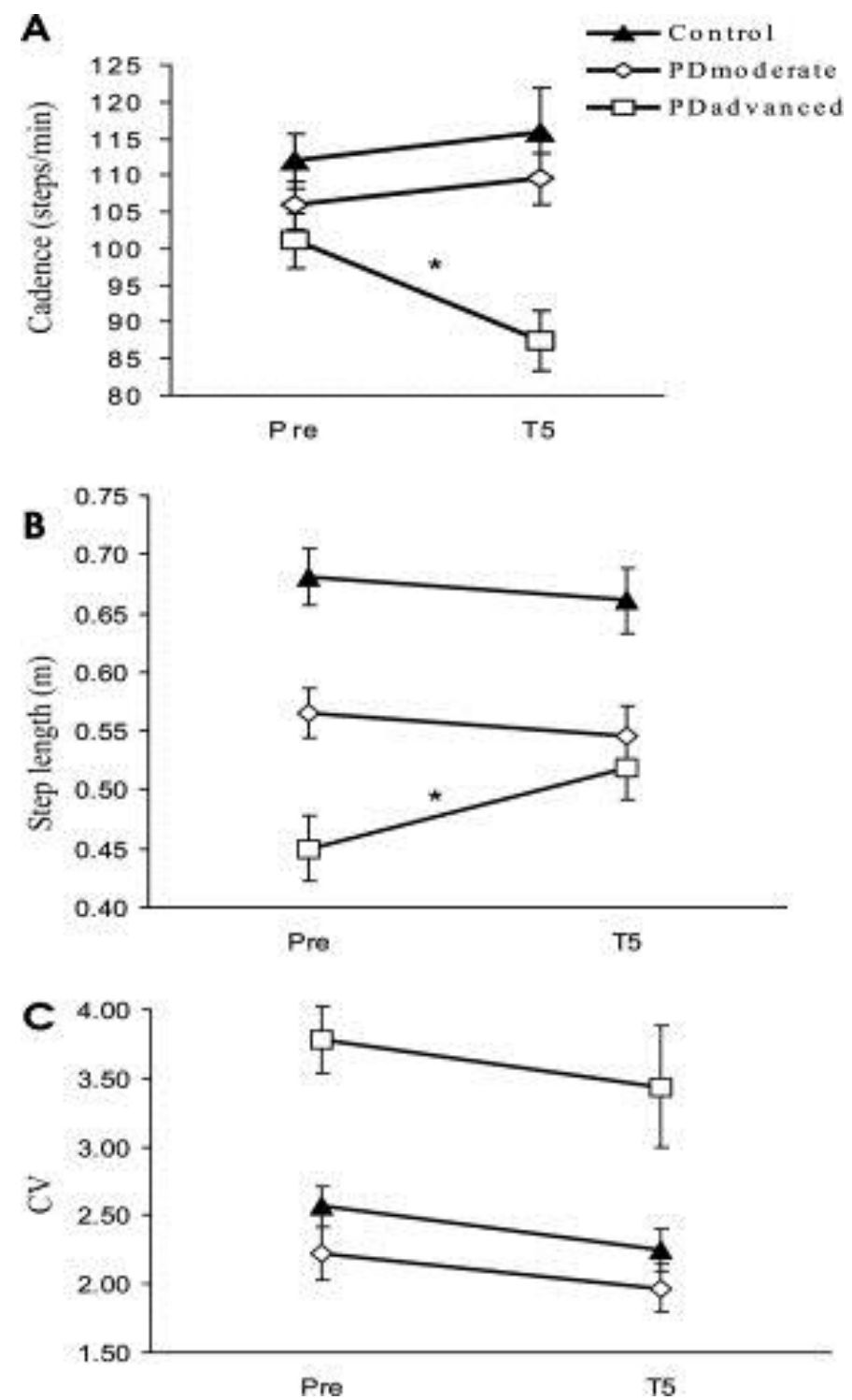

Figure 2 . Cadence (A), step length $(\mathbf{B})$, and CV $(\mathbf{C})$ before treadmill walking (Pre) and during treadmill walking (T5). Note that only the PD advanced group decreased significantly their step length and increased their cadence.

\section{Posttreadmill Effect}

Gait speed showed a significant main effect for time $\left(F_{3,63}=16.51, P \leq 0.001 ; \mathrm{EZ}=0.44 ; \mathrm{OP}=100 \%\right)$ and group $\left(F_{2,21}=21.25, P \leq 0.001 ; \mathrm{EZ}=0.98 ; \mathrm{OP}=100 \%\right)$, without a significant interaction. Since there were no significant interactions, to determine the time course for all the groups, we performed post-hoc $t$ tests grouping all the subjects together (patients and controls). The results showed that the speeds at Post1, Post2, and Post3 were significantly higher than before the treadmill $(t=4.86 P \leq 0.001, t=5.36 P$ $\leq 0.001, t=5.08 P \leq 0.001$ for Post1, Post2, and Post3, respectively) (Fig. 3A). 

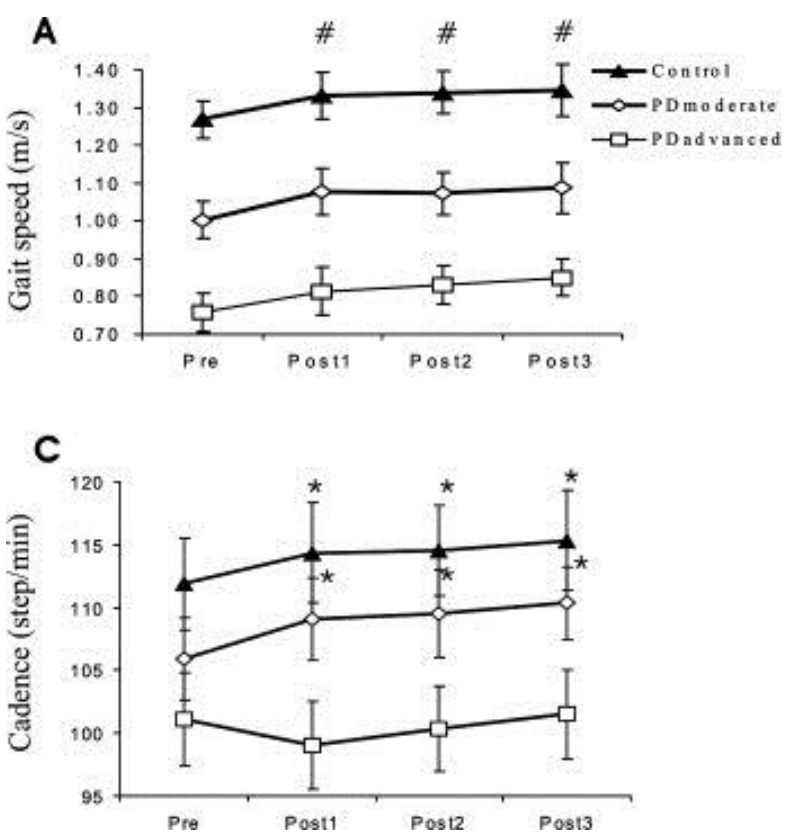

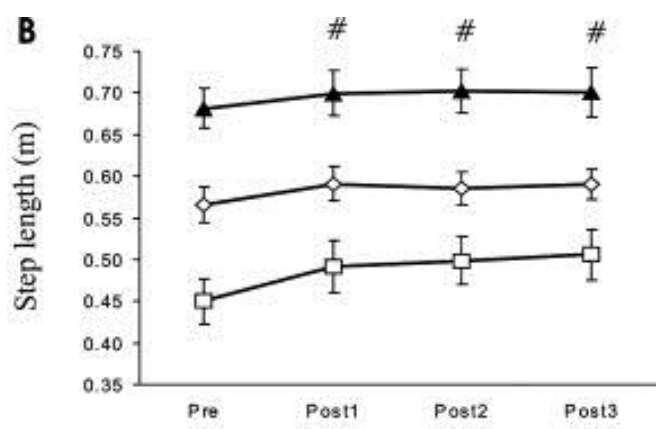

D

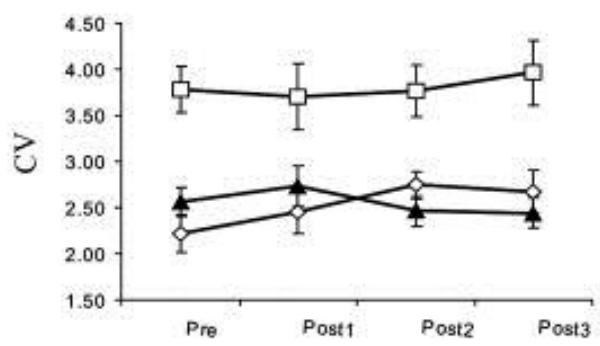

Figure 3. Comparison between overground walking before treadmill (Pre) and overground walking after treadmill (Post1, Post2, Post3). All subjects increased significantly their gait speed and the step length after the treadmill (A,B). The control and PD moderate groups increased significantly their cadence after the treadmill (C). No changes were shown in the CV (D)) (\#) indicate significant differences with Pre (patients and control subjects together). (*) indicate significant differences with Pre (for separate groups).

The step length showed a significant main effect for time $\left(F_{3,63}=13.03, P \leq 0.01\right.$; EZ $=0.38$; OP = $100 \%)$ and group $\left(F_{2,21}=17.58, P \leq 0.01 ; \mathrm{EZ}=0.98 ; \mathrm{OP}=100 \%\right)$ factors. No significant interaction between these factors was shown. Post-hoc $t$-tests showed significant increases of step length at Post1 $(t=$ 2.96, $P=0.02)$, Post2 $(t=2.72, P=0.02)$, and Post3 $(t=2.74, P=0.02)$ compared with the step length before the treadmill (Fig. 3B).

The cadence showed a significant main effect for time $\left(F_{3,63}=4.95, P \leq 0.01 ; \mathrm{EZ}=0.19 ; \mathrm{OP}=89 \%\right)$ and a significant difference between groups $\left(F_{2,21}=9.96, P \leq 0.01 ; \mathrm{EZ}=0.99 ; \mathrm{OP}=100 \%\right)$. The interaction group*time showed a trend for significance $\left(F_{6,63}=1.95, P=0.08\right.$; EZ $\left.=0.15 ; \mathrm{OP}=67 \%\right)$. Separate ANOVAs for each group showed a significant main effect for time for the control $\left(F_{3,21}=4.26\right.$, $P=0.02 ; \mathrm{EZ}=0.37 ; \mathrm{OP}=78 \%)$ and $\mathrm{PD}$ moderate $\left(F_{3,21}=6.18, P \leq 0.01 ; \mathrm{EZ}=0.54 ; \mathrm{OP}=69 \%\right)$ groups. Both the groups significantly increased their gait cadence immediately after the treadmill compared with pretreadmill ( $t=2.27, P \leq 0.05$ and $t=3.42, P=0.01$ for Control and PD moderate groups, respectively). During the Post2 and Post3, the cadence remained significantly higher than before the treadmill in the control subjects (Post2: $t=2.13, P=0.03$; Post3: $t=3.17, P=0.02$ ) and in the advanced PD patients (Post2: $t=3.01, P=0.02$; Post3: $t=3.19, P=0.02$ ) (Fig. 3C).

The CV showed significant differences between the groups $\left(F_{3,63}=20.26, P \leq 0.01\right)$, but not for the time (Fig. 3D).

\section{Discussion}

Our study shows that a single familiarization session over the treadmill leads to an improvement in the overground gait and lasts for at least $15 \mathrm{~min}$. However, the adaptation to the treadmill was different in the PD advanced group compared with PD moderate and control groups. This main difference was in the increased step length observed in the advanced PD patients. Moreover, the adaptation was followed by a "generalization effect" after the treadmill in all groups. 


\section{Group Characterization}

Our pretreadmill walking results are in line with several previous studies that showed a decrease in the speed and step length in PD patients, without any change in the step cadence.2, 3 These differences were more pronounced for the more advanced PD patients. Regarding the stride time variability, only the PD advanced group showed a higher CV than Control and PD moderate group. Thus, our groups were significantly different in their gait characteristics.

\section{Overground Gait vs. Treadmill}

When we compared the overground gait parameters before treadmill with the T5 block over the treadmill, we found the same behavior for the moderate PD patients and control subjects. Over the treadmill, both groups increased their cadence, although not significantly, and maintained a similar step length to walking overground. These results were reported previously by Frenkel-Toledo and coworkers17 in PD patients with Hoehn and Yahr stage of 2, the same stage that in moderate PD group in our study. However, the adaptation in the advanced PD patients (Hoehn and Yahr of 3) was opposite to the other two groups, increasing their step length and decreasing their cadence significantly. Thus, it seems that the treadmill affects differently the gait pattern in PD patients with more advanced PD. We found a trend for a decrease in stride time variability for treadmill vs. overground walking in all three groups. This is in line with evidence showing a significant decrease in the stride variability during treadmill walking in comparison with walking on ground with a walker.17 However, our results indicate that in advanced PD patients the step cadence and step length are more sensible to adapt and change to the treadmill than the stride time variability. It is of importance to note that the reduced step length is the main impairment of gait in PD patients, and most of the gait therapies are focused in the recovery of this parameter.

One hypothesized suggests that the adaptation to the treadmill is related to sensory cues. It had been suggested that external sensory cues can provide the necessary trigger in PD to switch from one movement component in a movement sequence to the next and thus bypass defective internal pallidocortical projections.19 It is possible that when the patients are walking on the treadmill they may be using the propioceptive cues of the belt as a pacemaker. However, one issue that has not been reported in the literature is how the visual information can affect the PD gait over the treadmill. Under normal lighting, visual cues from lines on the walking surface have been reported to improve the stride length in PD patients, due to the optical flow induced by the lines during the gait.20 Although a treadmill does not generate optical flow, it is important to note that the subjects could use the distance from the front of the treadmill as a static visual cue.

An alternative explanation for the changes in the gait pattern over the treadmill in our study could be the central pattern generators (CPG). The CPG has been postulated to explain the improvements in the gait of spinal cord injury patients during the use of a treadmill.21-23 The CPG consist of mutually inhibiting extensor and flexor half-center. Thus, during the stance phase, load is detected by Golgi tendon organs and muscle spindles of the extensor muscles and cutaneous afferents of the foot, which activates the extensor half-center. At the end of the stance phase, muscle spindles afferents of the flexor muscle excite the flexor half-center and initiate the swing phase.23, 24 The load sensitivity is reduced in PD patients resulting in poor leg extensor activation and increasing the tibial activation during the swing phase. 25 This rise could be due to a defective extensor suppression of the flexor generating circuitry.26 It has been suggested that while on the treadmill the subjects use appropriate sensory inputs such as hip extension and correct loading of the limbs.27 Moreover, during treadmill gait, the belt forces stepping, probably through stretch facilitation of hip flexors and ankle plantar flexors at the end of the stance phase.28 Thus, the treadmill training could rely on the adequate afferent activation of the CPG in PD patients.

\section{Posttreadmill Effect}

All the subjects increased their overground gait speed and step length after the treadmill session in comparison with pretreadmill walking. These results suggest a "generalization effect" by demonstrating that several bouts of treadmill practice carry over to an improvement in an untrained task in this case walking overground. These results are in line with previous studies that have reported gait improvements after one treadmill session. 12,14

The earlier speed increase after the treadmill could be due to the adaptation of the postural part of the gait initiation program. Lepers and colleagues 29 found that following a running exercise on a treadmill, 
the first step length and velocity were greater, the double stance phase duration was shorter and the center of foot pressure displayed some changes. Following this line, Zanetti and Schieppati30 showed that treadmill walking modified quiet stance control inducing a forward inclination of the body, lasting for a few minutes. This could explain the duration of this "generalization effect" reported in our study. On the other hand training with visual cues or attentional strategies can improve the step length, speed and double limb support duration for at least $2 \mathrm{hr} .31$ Moreover, some studies suggest that the treadmill can work as a form of motor learning.18, 23 Thus, motor learning and neuroplasticity could be possible mechanisms to explain the carryover effect.18, 23, 32-34

The present study confirms the potential therapeutic use of treadmill training for the rehabilitation of gait in PD patients. The use of the treadmill is effective in PD patients, leading to an increase in the step length and thus to the improvement of the main gait impairment in PD.

\section{Acknowledgements}

We thank Noa Fogelson for the revision of the manuscript.

\section{References}

1 Hoehn MM,Yahr MD. Parkinsonism: onset, progression and mortality. Neurology 1967; 17: 427-442.

2 Morris ME,Iansek R,Matyas TA,Summers JJ. Ability to modulate walking cadence remains intact in Parkinson's disease. J Neurol Neurosurg Psychiatry 1994; 57: 1532-1534.

3 Morris ME,Iansek R,Matyas TA,Summers JJ. The pathogenesis of gait hypokinesia in Parkinson's disease. Brain 1994; 117: 1169-1181.

4 Knutsson E. An analysis of Parkinsonian gait. Brain 1972; 95: 475-486.

5 Murray MP,Sepic SB,Gardner GM,Downs WJ. Walking patterns of men with parkinsonism. Am J Phys Med 1978; 57: 278-294.

6 Bowes SG,Clark PK,Leeman AL, et al. Determinants of gait in the elderly parkinsonian on maintenance levodopa/carbidopa therapy. Br J Clin Pharmacol 1990; 30: 13-24.

7 Blin O,Ferrandez AM,Serratrice G. Quantitative analysis of gait in Parkinson patients: increased variability of stride length. J Neurol Sci 1990; 98: 91-97.

8 Ueno E,Yanagisawa N,Takami M. Gait disorders in parkinsonism. A study with floor reaction forces and EMG. Adv Neurol 1993; 60: 414-418.

9 Hausdorff JM,Cudkowicz ME,Firtion R,Wei JY,Goldberger AL. Gait variability and basal ganglia disorders: strideto-stride variations of gait cycle timing in Parkinson's disease and Huntington's disease. Mov Disord 1998; 13: $428-437$.

10 Schenkman M. Physical therapy intervention for the ambulatory patient. In: TurnbullGI, editor. Physical therapy management of Parkinson's disease. New York: Churchill Livingstone; 1992. p 137-192.

11 Peppe A,Chiavalon C,Pasqualetti P,Crovato D,Caltagirone C. Does gait analysis quantify motor rehabilitation efficacy in Parkinson's disease patients? Gait Posture 2007; 26: 452-462.

12 Miyai I,Fujimoto Y,Ueda Y, et al. Treadmill training with body weight support: its effect on Parkinson's disease. Arch Phys Med Rehabil 2000; 81: 849-852.

13 Miyai I,Fujimoto Y,Yamamoto H, et al. Long-term effect of body weight-supported treadmill training in Parkinson's disease: a randomized controlled trial. Arch Phys Med Rehabil 2002; 83: 1370-1373.

14 Pohl M,Rockstroh G,Ruckriem S,Mrass G,Mehrholz J. Immediate effects of speed-dependent treadmill training on gait parameters in early Parkinson's disease. Arch Phys Med Rehabil 2003; 84: 1760-1766.

15 Toole T,Maitland CG,Warren E,Hubmann MF,Panton L. The effects of loading and unloading treadmill walking on balance, gait, fall risk, and daily function in Parkinsonism. NeuroRehabilitation 2005; 20: 307-322.

16 Protas EJ,Mitchell K,Williams A,Qureshy H,Caroline K,Lai EC. Gait and step training to reduce falls in Parkinson's disease. Neurorehabilitation 2005; 20: 183-190.

17 Frenkel-Toledo S,Giladi N,Peretz C,Herman T,Gruendlinger L,Hausdorff JM. Treadmill walking as an external pacemaker to improve gait rhythm and stability in Parkinson's disease. Mov Disord 2005; 20: 1109-1114.

18 Herman T,Giladi N,Gruendlinger L,Hausdorff JM. Six weeks of intensive treadmill training improves gait and quality of life in patients with Parkinson's disease: a pilot study. Arch Phys Med Rehabil 2007; 88: 1154-1158.

19 Cunnington R,Iansek R,Bradshaw JL,Phillips JG. Movement-related potentials in Parkinson's disease. Presence and predictability of temporal and spatial cues. Brain 1995; 118: 935-950.

20 Azulay JP,Mesure S,Amblard B,Blin O,Sangla I,Pouget J. Visual control of locomotion in Parkinson's disease. Brain 1999; 122: 111-120.

21 Dietz V,Colombo G. Recovery from spinal cord injury-underlying mechanisms and efficacy of rehabilitation. Acta Neurochir Suppl 2004; 89: 95-100.

22 Dietz V,Wirz M,Jensen L. Locomotion in patients with spinal cord injuries. Phys Ther 1997; 77: 508-516.

23 Van de Crommert HW,Mulder T,Duysens J. Neural control of locomotion: sensory control of the central pattern generator and its relation to treadmill training. Gait Posture 1998; 7: 251-263.

24 Pearson KG. Proprioceptive regulation of locomotion. Curr Opin Neurobiol 1995; 5: 786-791.

25 Dietz V,Colombo G. Influence of body load on the gait pattern in Parkinson's disease. Mov Disord 1998; 13: 255 261. 
26 Dietz V,Duysens J. Significance of load receptor input during locomotion: a review. Gait Posture 2000; 11: 102110.

27 Barbeau H. Locomotor training in neurorehabilitation: emerging rehabilitation concepts. Neurorehabil Neural Repair 2003; 17: 3-11.

28 Shepherd R,Carr J. Treadmill walking in neurorehabilitation. Neurorehabil Neural Repair 1999; 13: 171-173.

29 Lepers R,Breniere Y,Maton B. Changes to the gait initiation programme following a running exercise in human subjects. Neurosci Lett 1999; 260: 69-73.

30 Zanetti C,Schieppati M. Quiet stance control is affected by prior treadmill but not overground locomotion. Eur J Appl Physiol 2007; 100: 331-339.

31 Morris ME,Iansek R,Matyas TA,Summers JJ. Stride length regulation in Parkinson's disease. Normalization strategies and underlying mechanisms. Brain 1996; 119: 551-568.

32 Fox CM,Ramig LO,Ciucci MR,Sapir S,McFarland DH,Farley BG. The science and practice of LSVT/LOUD: neural plasticity-principled approach to treating individuals with Parkinson disease and other neurological disorders. Semin Speech Lang 2006; 27: 283-299.

33 Lehman DA,Toole T,Lofald D,Hirsch MA. Training with verbal instructional cues results in near-term improvement of gait in people with Parkinson disease. J Neurol Phys Ther 2005; 29: 2-8.

34 Nieuwboer A,Kwakkel G,Rochester L, et al. Cueing training in the home improves gait-related mobility in Parkinson's disease: the RESCUE trial. J Neurol Neurosurg Psychiatry 2007; 78: 134-140. 